\title{
Common fixed point of mappings satisfying rational inequalities in ordered complex valued generalized metric spaces
}

\author{
Mujahid Abbas • Vesna Ćojbašić Rajić • \\ Talat Nazir • Stojan Radenović
}

Received: 9 April 2013 / Accepted: 9 July 2013 / Published online: 24 July 2013

(C) The Author(s) 2013. This article is published with open access at Springerlink.com

\begin{abstract}
Azam et al. (Numer Funct Anal Optim, 32(3):243-253, 2011) introduced a notion of complex valued metric space and obtained common fixed point result for mappings in such spaces. In this paper, introducing the concept of complex valued generalized metric spaces, some fixed and common fixed point results are obtained. As an application, periodic point property of common fixed point problem for two rational type contractive mappings involved therein is established.
\end{abstract}

Keywords Weakly increasing map - Common fixed point - Periodic point .

Complex valued generalized metric spaces · Partially ordered set · BA-cone metric space

Mathematics Subject Classification: $\quad 47 \mathrm{H} 10 \cdot 54 \mathrm{H} 25 \cdot 54 \mathrm{E} 50$

\section{Introduction and Preliminaries}

Fixed point theory is one of the well known traditional theories in mathematics that has a broad set of applications. Banach's contraction principle gives appropriate and simple

\footnotetext{
M. Abbas

Department of Mathematics and Applied Mathematics, University of Pretoria, Lynnwood road, Pretoria 0002, South Africa

e-mail: mujahid.abbas@up.ac.za

V. Ćojbašić Rajić

Faculty of Economics, University of Belgrade, Kamenička 6, 11000 Beograd, Serbia

e-mail: vesnac@ekof.bg.ac.rs

T. Nazir

Department of Mathematics, COMSATS Institute of Information Technology, 22060 Abbottabad, Pakistan

e-mail: talat@ ciit.net.pk

S. Radenović $(\varangle)$

Faculty of Mechanical Engineering, University of Belgrade, Kraljice Marije 16, 11120 Beograd, Serbia e-mail: radens@beotel.rs
} 
conditions to establish the existence and uniqueness of a solution of an operator equation $T x=x$. This principal is constructive in nature and is one of the most useful tools in the study of nonlinear equations. There are many generalizations of the Banach's contraction mapping principle in the literature. These generalization were made either by using the contractive condition or by imposing some additional conditions on an ambient space. There have been a number of generalizations of metric spaces such as, rectangular metric spaces, pseudo metric spaces, fuzzy metric spaces, quasi metric spaces, partial metric spaces, probabilistic metric spaces, D-metric spaces and cone metric spaces (see [1,10,15,20,25]). Branciari [8] introduced the notion of a generalized metric space replacing the triangle inequality by a rectangular type inequality. He then extended Banach's contraction principle in such spaces. In 2008, Azam et al. [6] obtained sufficient conditions for existence of unique fixed point of Kannan type mappings defined on generalized metric spaces. Samet [28] and Sarma et al. [29] showed that some propositions in [8] are not true. Moreover, in [29], a rigorous and nice proof of the Banach's contraction principle is presented, by assuming that the generalized metric space is Hausdorff. Common fixed point problem for two maps under several variants of non-commutativity has been studied by many authors. Recently, Azam et al. [7] obtained the generalization of Banach's contraction principal introducing the concept of a complex valued metric space. The existence of fixed points in ordered metric spaces has been initiated in 2004 by Ran and Reurings [22], and further studied by Nieto and Lopez [18]. Several authors have studied the problem of existence and uniqueness of a fixed point for mappings satisfying different contractive conditions in the framework of partially ordered metric spaces (see for example $[2-5,9,12,21,24]$ ).

The aim of this paper is to introduce the concept of a complex valued generalized metric space and to study the fixed and common fixed point results for two mappings satisfying rational inequalities, without exploiting any type of commutativity condition. The results presented in this paper substantially extend and strengthen the results given in [7] and [23].

Consistent with Azam et al. [7] and [23], the following definitions and results will be needed in the sequel.

Let $\mathbb{C}$ be the set of complex numbers and let $z_{1}, z_{2} \in \mathbb{C}$. Define a partial order $\leq$ on $\mathbb{C}$ as follows: $z_{1} \leq z_{2}$ if and only if $\operatorname{Re}\left(z_{1}\right) \leq \operatorname{Re}\left(z_{2}\right), \operatorname{Im}\left(z_{1}\right) \leq \operatorname{Im}\left(z_{2}\right)$.

It follows that $z_{1} \leq z_{2}$ if one of the following conditions is satisfied:

(1) $\operatorname{Re}\left(z_{1}\right)=\operatorname{Re}\left(z_{2}\right), \operatorname{Im}\left(z_{1}\right)<\operatorname{Im}\left(z_{2}\right)$,

(2) $\operatorname{Re}\left(z_{1}\right)<\operatorname{Re}\left(z_{2}\right), \operatorname{Im}\left(z_{1}\right)=\operatorname{Im}\left(z_{2}\right)$,

(3) $\operatorname{Re}\left(z_{1}\right)<\operatorname{Re}\left(z_{2}\right), \operatorname{Im}\left(z_{1}\right)<\operatorname{Im}\left(z_{2}\right)$,

(4) $\operatorname{Re}\left(z_{1}\right)=\operatorname{Re}\left(z_{2}\right), \operatorname{Im}\left(z_{1}\right)=\operatorname{Im}\left(z_{2}\right)$.

In particular, we will write $z_{1} \leq z_{2}$ if one of (1), (2) and (3) is satisfied and we will write $z_{1}<z_{2}$ if only (3) is satisfied.

Some elementary properties of the partial order $\leq$ on $\mathbb{C}$ are the following:

(i) If $0 \leq z_{1} \leq z_{2}$, then $\left|z_{1}\right| \leq\left|z_{2}\right|$.

(ii) $z_{1} \leq z_{2}$ is equivalent to $z_{1}-z_{2} \leq 0$.

(iii) If $z_{1} \leq z_{2}$ and $r \geq 0$ is a real number, then $r z_{1} \leq r z_{2}$.

(iv) If $0 \leq z_{1}$ and $0 \leq z_{2}$ with $z_{1}+z_{2} \neq 0$, then $\frac{z_{1}^{2}}{z_{1}+z_{2}} \leq z_{1}$.

(v) $0 \leq z_{1}$ and $0 \leq z_{2}$ do not imply $0 \leq z_{1} z_{2}$.

(vi) $0 \leq z_{1}$ does not imply $0 \leq \frac{1}{z_{1}}$. Moreover, if $0<z_{1}$ and $0 \leq \frac{1}{z_{1}}$, then $\operatorname{Im}\left(z_{1}\right)=0$.

Now we give the definition of complex valued generalized metric space. 
Definition 1.1 Let $X$ be a nonempty set. If a mapping $d: X \times X \rightarrow \mathbb{C}$ satisfies:

(a) $0 \leq d(x, y)$ for all $x, y \in X$ and $d(x, y)=0$ if and only if $x=y$;

(b) $d(x, y)=d(y, x)$ for all $x, y \in X$;

(c) $d(x, y) \leq d(x, u)+d(u, v)+d(v, y)$ for all $x, y \in X$ and all distinct $u, v \in X$ each one is different from $x$ and $y$.

Then $d$ is called a complex valued generalized metric on $X$ and $(X, d)$ is called a complex valued generalized metric space.

Example 1.2 Let $X=\{-1,1,-i, i\}$. Define $d: X \times X \rightarrow \mathbb{C}$ as follows:

$$
\begin{aligned}
d(1,-1) & =d(-1,1)=3 e^{i \theta}, \\
d(-1, i) & =d(i,-1)=d(1, i)=d(i, 1)=e^{i \theta}, \\
d(1,-i) & =d(-i, 1)=d(-1,-i)=d(-i,-1)=d(i,-i)=d(-i, i)=5 e^{i \theta}, \\
d(1,1) & =d(-1,-1)=d(i, i)=d(-i,-i)=0 .
\end{aligned}
$$

It is easy to verify that $(X, d)$ is a complex valued generalized metric space when $\theta \in\left[0, \frac{\pi}{2}\right]$. Note that

$$
3 e^{i \theta}=d(1,-1)>d(1, i)+d(i,-1)=2 e^{i \theta} .
$$

So $d$ is not a complex valued metric.

The next example gives a method to construct a new complex valued generalized metric space from a family of given generalized metric spaces.

Example 1.3 Let $\left\{\left(X_{n}, d_{n}\right): n \in K \subset \mathbb{N}\right\}$ be a family of disjoint complex valued generalized metric spaces and let $X=\bigcup\left\{X_{n}: n \in K\right\}$. Define, for all $x, y \in X$, a mapping $d: X \times X \rightarrow$ $\mathbb{C}$ by

$$
d(x, y)= \begin{cases}d_{n}(x, y), & \text { if } x, y \in X_{n}, \text { for some } n \in K \\ 1, & \text { if } x \in X_{n}, y \in X_{m} \text { for some } m, n \in K, m \neq n .\end{cases}
$$

Clearly, $(X, d)$ is a complex valued generalized metric space.

Let $X$ be a complex valued generalized metric space and $A \subseteq X$. A point $x \in X$ is called an interior point of a set $A$ whenever there exists $0<r \in \mathbb{C}$ such that $B(x, r)=\{y \in$ $X: d(x, y)<r\} \subseteq A$. A subset $A$ in $X$ is called open whenever each point of $A$ is an interior point of $A$. The family $F=\{B(x, r): x \in X, 0<r\}$ is a sub-basis for a Hausdorff topology $\tau$ on $X$.

A point $x \in X$ is called a limit point of $A$ whenever for every $0<r \in \mathbb{C}, B(x, r) \cap(A \backslash x) \neq$ $\phi$. A subset $B \subseteq X$ is called closed whenever each limit point of $B$ belongs to $B$.

Let $\left\{x_{n}\right\}$ be a sequence in $X$ and $x \in X$. If for every $c \in \mathbb{C}$, with $0<c$ there is $n_{0} \in \mathbb{N}$ such that for all $n>n_{0}, d\left(x_{n}, x\right)<c$, then $x$ is called the limit of $\left\{x_{n}\right\}$ and we write $\lim _{n \rightarrow \infty} x_{n}=x$ or $x_{n} \rightarrow x$ as $n \rightarrow \infty$. If for every $c \in \mathbb{C}$, with $0<c$, there is an $n_{0} \in \mathbb{N}$ such that for all $n, m>n_{0}, d\left(x_{n}, x_{m}\right)<c$, then $\left\{x_{n}\right\}$ is called a Cauchy sequence in $X$. If every Cauchy sequence is convergent in $X$, then it is called a complete complex valued generalized metric space.

Lemma 1.4 Let $X$ be a complex valued generalized metric space and $\left\{x_{n}\right\}$ a sequence in $X$. Then $\left\{x_{n}\right\}$ converges to $x$ if and only if $\left|d\left(x_{n}, x\right)\right| \rightarrow 0$ as $n \rightarrow \infty$. 
Lemma 1.5 Let $X$ be a complex valued generalized metric space and $\left\{x_{n}\right\}$ a sequence in $X$. Then $\left\{x_{n}\right\}$ is a Cauchy sequence if and only if $\left|d\left(x_{n}, x_{m}\right)\right| \rightarrow 0$ as $n, m \rightarrow \infty$.

The following definition is due to Altun([3]).

Definition 1.6 [3] Let $(X, \preceq)$ be a partially ordered set. A pair $(f, g)$ of self-maps of $X$ is said to be weakly increasing if $f x \preceq g f x$ and $g x \preceq f g x$ for all $x \in X$. If $f=g$, then we have $f x \preceq f^{2} x$ for all $x$ in $X$ and in this case, we say that $f$ is a weakly increasing map.

Example 1.7 Let $X=\mathbb{R}^{+}$be endowed with usual ordering. Let $f: X \rightarrow X$ be defined by

$$
f x= \begin{cases}x^{\frac{1}{4}}, & \text { if } 0 \leq x \leq 1 \\ x, & \text { if } 1<x \leq 4 \\ 0, & \text { if } 4<x<\infty\end{cases}
$$

Note that if $x \in[0,1]$, then $f x=x^{\frac{1}{4}} \leq x^{\frac{1}{16}}=f^{2} x$. Also when $x \in(1,4]$, then $f x=x \leq$ $f^{2} x$ and if $x \in(4, \infty)$, then $f x=0=f^{2} x$. Thus $f x \leq f^{2} x$ for all $x$ in $X$ an so $f$ is a weakly increasing map. Note that $f$ not increasing since $3<5$ and $f(3)=3 \not \leq 0=f(5)$.

A point $x$ in $X$ said to be a fixed point of a self-map $f$ on $X$ if $f x=x$. A fixed point problem is to find some $x$ in $X$ such that $f x=x$ and we denote it by $F P(f, X)$. A point $x \in X$ is called a common fixed point of pair $(f, g)$ if $x=f x=g x$, where $f$ and $g$ are two self-maps on $X$. A common fixed point problem is to find some $x$ in $X$ such that $x=f x=g x$, and we denote it by $C F P(f, g, X)$. A nonempty subset $W$ of a partially ordered set $X$ is said to be totally ordered if every two elements of $W$ are comparable.

\section{Main Results}

In this section, we prove a common fixed point result for weakly increasing maps on an ordered complex valued generalized metric space.

Theorem 2.1 Let $(X, \preceq)$ be a partially ordered set such that there exists a complete complex valued generalized metric $d$ on $X$ and $(S, T)$ a pair of weakly increasing self-maps on $X$. Suppose that, for every comparable $x, y \in X$ we have either

$$
\begin{gathered}
d(S x, T y) \leq \frac{a_{1}\left[d(y, S x) d(x, T y)^{2}+d(x, T y) d(y, S x)^{2}\right]}{d(x, T y)^{2}+d(y, S x)^{2}}+\frac{a_{2} d(x, T y) d(y, S x)}{d(x, T y)+d(y, S x)} \\
+a_{3} d(x, S x)+a_{4} d(y, T y)+a_{5} d(x, y),
\end{gathered}
$$

in case $d(x, T y)+d(y, S x) \neq 0, a_{i} \geq 0$ for $i=1$ to 5 and $\sum_{i=1}^{5} a_{i}<1$, or

$$
d(S x, T y)=0 \text { if } d(x, T y)+d(y, S x)=0 .
$$

If $S$ or $T$ is continuous or for any nondecreasing sequence $x_{n}$ with $x_{n} \rightarrow z$ in $X$ we necessarily have $x_{n} \preceq z$ for all $n \in \mathbb{N}$, then $S$ and $T$ have a common fixed point. Moreover, the set of common fixed points of $S$ and $T$ is totally ordered if and only if $S$ and $T$ have one and only one common fixed point.

Proof First we shall show that if $S$ or $T$ has a fixed point, then it is a common fixed point of $S$ and $T$. Let $u$ be a fixed point of $S$. Then from (2.1) with $x=y=u$, we have for $u \neq T u$ : 


$$
\begin{aligned}
d(u, T u)= & d(S u, T u) \\
\leq & \frac{a_{1}\left[d(u, S u)\{d(u, T u)\}^{2}+d(u, T u)\{d(u, S u)\}^{2}\right]}{\{d(u, T u)\}^{2}+\{d(u, S u)\}^{2}}+\frac{a_{2} d(u, T u) d(u, S u)}{d(u, T u)+d(u, S u)} \\
& +a_{3} d(u, S u)+a_{4} d(u, T u)+a_{5} d(u, u) \\
= & \frac{a\left[d(u, u)\{d(u, T u)\}^{2}+d(u, T u)\{d(u, u)\}^{2}\right]}{\{d(u, T u)\}^{2}+\{d(u, u)\}^{2}}+\frac{a_{2} d(u, T u) d(u, u)}{d(u, T u)+d(u, u)} \\
& +a_{3} d(u, u)+a_{4} d(u, T u) \\
= & a_{4} d(u, T u),
\end{aligned}
$$

which implies that $|d(u, T u)| \leq a_{4}|d(u, T u)|$. As $a_{4}<1$ so we have $d(u, T u)=0$ and $u$ is a common fixed point of $S$ and $T$. Similarly, if $u$ is a fixed point of $T$, then it is also fixed point of $S$.

Now let $x_{0}$ be an arbitrary point of $X$. If $S x_{0}=x_{0}$, then the proof is finished. Assume that $S x_{0} \neq x_{0}$. Construct a sequence $\left\{x_{n}\right\}$ in $X$ as follows:

$$
\begin{aligned}
& x_{1}=S x_{0} \preceq T S x_{0}=T x_{1}=x_{2}, \text { and } \\
& x_{2}=T x_{1} \preceq S T x_{1}=S x_{2}=x_{3} .
\end{aligned}
$$

Continuing this way, we have $x_{1} \preceq x_{2} \preceq \cdots \preceq x_{n} \preceq x_{n+1} \preceq \cdots$. Assume that $d\left(x_{2 n}, x_{2 n+1}\right)>0$, for every $n \in \mathbb{N}$. If not, then $x_{2 n}=x_{2 n+1}$ for some $n$. For all those $n, x_{2 n}=x_{2 n+1}=S x_{2 n}$ and the proof is finished. Assume that $d\left(x_{2 n}, x_{2 n+1}\right)>0$ for $n=0,1,2,3, \ldots$ As $x_{2 n}$ and $x_{2 n+1}$ are comparable, so we have

$$
\begin{aligned}
d\left(x_{2 n+1}, x_{2 n+2}\right)= & d\left(S x_{2 n}, T x_{2 n+1}\right) \\
\leq & \frac{a_{1}\left[d\left(x_{2 n+1}, S x_{2 n}\right)\left\{d\left(x_{2 n}, T x_{2 n+1}\right)\right\}^{2}+d\left(x_{2 n}, T x_{2 n+1}\right)\left\{d\left(x_{2 n+1}, S x_{2 n}\right)\right\}^{2}\right]}{\left\{d\left(x_{2 n}, T x_{2 n+1}\right)\right\}^{2}+\left\{d\left(x_{2 n+1}, S x_{2 n}\right)\right\}^{2}} \\
& +\frac{a_{2} d\left(x_{2 n}, T x_{2 n+1}\right) d\left(x_{2 n+1}, S x_{2 n}\right)}{d\left(x_{2 n}, T x_{2 n+1}\right)+d\left(x_{2 n+1}, S x_{2 n}\right)}+a_{3} d\left(x_{2 n}, S x_{2 n}\right)+a_{4} d\left(x_{2 n+1}, T x_{2 n+1}\right) \\
& +a_{5} d\left(x_{2 n}, x_{2 n+1}\right) \\
= & \frac{a_{1}\left[d\left(x_{2 n+1}, x_{2 n+1}\right)\left\{d\left(x_{2 n}, x_{2 n+2}\right)\right\}^{2}+d\left(x_{2 n}, x_{2 n+2}\right)\left\{d\left(x_{2 n+1}, x_{2 n+1}\right)\right\}^{2}\right]}{\left\{d\left(x_{2 n}, x_{2 n+2}\right)\right\}^{2}+\left\{d\left(x_{2 n+1}, x_{2 n+1}\right)\right\}^{2}} \\
& +\frac{a_{2} d\left(x_{2 n}, x_{2 n+2}\right) d\left(x_{2 n+1}, x_{2 n+1}\right)}{d\left(x_{2 n}, x_{2 n+2}\right)+d\left(x_{2 n+1}, x_{2 n+1}\right)}+a_{3} d\left(x_{2 n}, x_{2 n+1}\right)+a_{4} d\left(x_{2 n+1}, x_{2 n+2}\right) \\
& +a_{5} d\left(x_{2 n}, x_{2 n+1}\right) \\
= & \left(a_{3}+a_{5}\right) d\left(x_{2 n}, x_{2 n+1}\right)+a_{4} d\left(x_{2 n+1}, x_{2 n+2}\right),
\end{aligned}
$$

which implies that $d\left(x_{2 n+1}, x_{2 n+2}\right) \leq h d\left(x_{2 n}, x_{2 n+1}\right)$ for all $n \geq 0$, where $0 \leq h=$ $\frac{a_{3}+a_{5}}{1-a_{4}}<1$. Similarly, $d\left(x_{2 n}, x_{2 n+1}\right) \leq h d\left(x_{2 n-1}, x_{2 n}\right)$ for all $n \geq 0$. Hence for all $n \geq 0$, we have $d\left(x_{n+1}, x_{n+2}\right) \leq h d\left(x_{n}, x_{n+1}\right)$. Consequently

$$
d\left(x_{n+1}, x_{n+2}\right) \leq h d\left(x_{n}, x_{n+1}\right) \leq \ldots \leq h^{n+1} d\left(x_{0}, x_{1}\right)
$$

for all $n \geq 0$. Now for $m>n$, we have

$$
\begin{aligned}
d\left(x_{n}, x_{m}\right) & \leq d\left(x_{n}, x_{n+1}\right)+d\left(x_{n+1}, x_{n+2}\right)+\cdots+d\left(x_{m+1}, x_{m}\right) \\
& \leq h^{n} d\left(x_{0}, x_{1}\right)+h^{n+1} d\left(x_{0}, x_{1}\right)+\cdots+h^{m-1} d\left(x_{0}, x_{1}\right) \\
& \leq \frac{h^{n}}{1-h} d\left(x_{0}, x_{1}\right) .
\end{aligned}
$$


Therefore, $\left|d\left(x_{n}, x_{m}\right)\right| \leq \frac{h^{n}}{1-h}\left|d\left(x_{0}, x_{1}\right)\right|$. So $\left|d\left(x_{n}, x_{m}\right)\right| \rightarrow 0$ as $n, m \rightarrow \infty$ gives that $\left\{x_{n}\right\}$ is a Cauchy sequence in $X$. Since $X$ is complete, the sequence $\left\{x_{n}\right\}$ converges to a point $u$ in $X$.

If $S$ or $T$ is continuous, then it is clear that $S u=u=T u$.

If neither $S$, nor $T$ is continuous, then by given assumption $x_{n} \preceq u$ for all $n \in \mathbb{N}$. We claim that $u$ is a fixed point of $S$. If not, then $d(u, S u)=z>0$. From (2.1), we obtain

$$
\begin{aligned}
z \leq & d\left(u, x_{n+1}\right)+d\left(x_{n+1}, x_{n+2}\right)+d\left(x_{n+2}, S u\right) \\
= & d\left(u, x_{n+1}\right)+d\left(x_{n+1}, x_{n+2}\right)+d\left(S u, T x_{n+1}\right) \\
\leq & d\left(u, x_{n+1}\right)+d\left(x_{n+1}, x_{n+2}\right)+\frac{a_{1}\left[d\left(x_{n+1}, S u\right)\left\{d\left(u, T x_{n+1}\right)\right\}^{2}+d\left(u, T x_{n+1}\right)\left\{d\left(x_{n+1}, S u\right)\right\}^{2}\right]}{\left\{d\left(u, T x_{n+1}\right)\right\}^{2}+\left\{d\left(x_{n+1}, S u\right)\right\}^{2}} \\
& +\frac{a_{2} d\left(u, T x_{n+1}\right) d\left(x_{n+1}, S u\right)}{d\left(u, T x_{n+1}\right)+d\left(x_{n+1}, S u\right)}+a_{3} d(u, S u)+a_{4} d\left(x_{n+1}, T x_{n+1}\right)+a_{5} d\left(u, x_{n+1}\right) \\
= & d\left(u, x_{n+1}\right)+d\left(x_{n+1}, x_{n+2}\right)+\frac{a_{1}\left[d\left(x_{n+1}, S u\right)\left\{d\left(u, x_{n+2}\right)\right\}^{2}+d\left(u, x_{n+2}\right)\left\{d\left(x_{n+1}, S u\right)\right\}^{2}\right]}{\left\{d\left(u, x_{n+2}\right)\right\}^{2}+\left\{d\left(x_{n+1}, S u\right)\right\}^{2}} \\
& +\frac{a_{2} d\left(u, x_{n+2}\right) d\left(x_{n+1}, S u\right)}{d\left(u, x_{n+2}\right)+d\left(x_{n+1}, S u\right)}+a_{3} d(u, S u)+a_{4} d\left(x_{n+1}, x_{n+2}\right)+a_{5} d\left(u, x_{n+1}\right),
\end{aligned}
$$

and so

$$
\begin{aligned}
|z| \leq & \left|d\left(u, x_{n+1}\right)\right|+\left|d\left(x_{n+1}, x_{n+2}\right)\right| \\
& +\frac{a_{1}\left[\left|d\left(x_{n+1}, S u\right)\right|\left\{\left|d\left(u, x_{n+2}\right)\right|\right\}^{2}+\left|d\left(u, x_{n+2}\right)\right|\left\{\left|d\left(x_{n+1}, S u\right)\right|\right\}^{2}\right]}{\left|\left\{d\left(u, x_{n+2}\right)\right\}^{2}+\left\{d\left(x_{n+1}, S u\right)\right\}^{2}\right|} \\
& +\frac{a_{2}\left|d\left(u, x_{n+2}\right)\right|\left|d\left(x_{n+1}, S u\right)\right|}{\left|d\left(u, x_{n+2}\right)+d\left(x_{n+1}, S u\right)\right|}+a_{3}|d(u, S u)| \\
& +a_{4}\left|d\left(x_{n+1}, x_{n+2}\right)\right|+a_{5}\left|d\left(u, x_{n+1}\right)\right|,
\end{aligned}
$$

which on taking limit as $n \rightarrow \infty$ gives $|z| \leq a_{3}|z|$, a contradiction, and so $u=S u$. Therefore $S u=T u=u$.

Now suppose that set of common fixed points of $S$ and $T$ is totally ordered. We prove that common fixed point of $S$ and $T$ is unique. Assume on contrary that $u$ and $v$ are distinct common fixed points of $S$ and $T$. By supposition, we can replace $x$ by $u$ and $y$ by $v$ in $(2.1 ;)$ to obtain

$$
\begin{aligned}
d(u, v)= & d(S u, T v) \\
\leq & \frac{a_{1}\left[\{d(v, S u) d(u, T v)\}^{2}+d(u, T v)\{d(v, S u)\}^{2}\right]}{\{d(u, T v)\}^{2}+\{d(v, S u)\}^{2}}+\frac{a_{2} d(u, T v) d(v, S u)}{d(u, T v)+d(v, S u)} \\
& +a_{3} d(u, S u)+a_{4} d(v, T v)+a_{5} d(u, v) \\
= & \frac{a_{1}\left[\{d(v, u) d(u, v)\}^{2}+d(u, v)\{d(v, u)\}^{2}\right]}{\{d(u, v)\}^{2}+\{d(v, u)\}^{2}}+\frac{a_{2} d(u, v) d(v, u)}{d(u, v)+d(v, u)} \\
& +a_{3} d(u, u)+a_{4} d(v, v)+a_{5} d(u, v) \\
= & \left(a_{1}+\frac{a_{2}}{2}+a_{5}\right) d(u, v),
\end{aligned}
$$

which implies that $|d(u, v)| \leq\left(a_{1}+\frac{a_{2}}{2}+a_{5}\right)|d(u, v)|$, a contradiction. Hence $u=v$.

Conversely, if $S$ and $T$ have only one common fixed point then the set of common fixed point of $S$ and $T$ being singleton is totally ordered. 
Although we studied a common fixed point problem for two mappings to consider a more general result, we could use even one and yet the result would have been new. In Theorem 2.1 , take $S=T$, to obtain the following corollary.

Corollary 2.2 Let $(X, \preceq)$ be a partially ordered set such that there exists a complete complex valued generalized metric $d$ on $X$ and let $T$ be a weakly increasing self-map on $X$. Suppose that, for every comparable $x, y \in X$, either

$$
\begin{aligned}
d(T x, T y) \leq & \frac{a_{1}\left[d(y, T x) d(x, T y)^{2}+d(x, T y) d(y, T x)^{2}\right]}{d(x, T y)^{2}+d(y, T x)^{2}}+\frac{a_{2} d(x, T y) d(y, T x)}{d(x, T y)+d(y, T x)} \\
& +a_{3} d(x, T x)+a_{4} d(y, T y)+a_{5} d(x, y),
\end{aligned}
$$

if $d(x, T y)+d(y, T x) \neq 0, a_{i} \geq 0$ for $i=1$ to 5 and $\sum_{i=1}^{5} a_{i}<1$, or

$$
d(T x, T y)=0 \text { if } d(x, T y)+d(y, T x)=0 .
$$

If $T$ is continuous or for a nondecreasing sequence $\left\{x_{n}\right\}$ with $x_{n} \rightarrow z$ in $X$ we necessarily have $x_{n} \preceq z$ for all $n \in \mathbb{N}$, then $T$ has a fixed point. Moreover, the set of fixed points of $T$ is totally ordered if and only if $T$ has one and only one fixed point.

Theorem 2.3 Let $(X, \preceq)$ be a partially ordered set such that there exists a complete complex valued generalized metric $d$ on $X$ and a pair $(S, T)$ weakly increasing self-maps on $X$. Suppose that, for every comparable $x, y \in X$, either

$$
\begin{aligned}
d(S x, T y) \leq & \frac{a[d(x, S x) d(x, T y)+d(y, T y) d(y, S x)]}{d(x, T y)+d(y, S x)} \\
& +\frac{b d(x, T y) d(y, S x)}{d(x, S x)+d(y, T y)}
\end{aligned}
$$

if $d(x, T y)+d(y, S x) \neq 0$ and $d(x, S x)+d(y, T y) \neq 0$, where $a, b \geq 0$ with $a+b<1$, or

$$
d(S x, T y)=0 \quad \text { if } d(x, T y)+d(y, S x)=0 \quad \text { or } \quad d(x, S x)+d(y, T y)=0 .
$$

If $S$ or $T$ is continuous or for a nondecreasing sequence $\left\{x_{n}\right\}$ with $x_{n} \rightarrow z$ in $X$ we necessarily have $x_{n} \preceq z$ for all $n \in \mathbb{N}$. Then $S$ and $T$ have a common fixed point. Moreover, the set of common fixed points of $S$ and $T$ is totally ordered if and only if $S$ and $T$ have one and only one common fixed point.

Proof First we shall show that if $S$ or $T$ has a fixed point, then it is a common fixed point of $S$ and $T$. Indeed, let $u$ be a fixed point of $S$. Then from (2.5) with $x=y=u$, we have for $u \neq T u$ :

$$
\begin{aligned}
d(u, T u) & =d(S u, T u) \\
& \leq \frac{a[d(u, S u) d(u, T u)+d(u, T u) d(u, S u)]}{d(u, T u)+d(u, S u)}+\frac{b d(u, T u) d(u, S u)}{d(u, S u)+d(u, T u)} \\
& =\frac{a[d(u, u) d(u, T u)+d(u, T u) d(u, u)]}{d(u, T u)+d(u, u)}+\frac{b d(u, T u) d(u, u)}{d(u, u)+d(u, T u)} \\
& =0 .
\end{aligned}
$$

Hence $d(u, T u)=0$ and so $u$ is a common fixed point of $S$ and $T$. Similarly if $u$ is a fixed point of $T$, then it is also fixed point of $S$. 
Now let $x_{0}$ be an arbitrary point of $X$. If $S x_{0}=x_{0}$, then the proof is finished. Assume that $S x_{0} \neq x_{0}$. Define a sequence $x_{n}$ in $X$ as follows:

$$
\begin{aligned}
& x_{1}=S x_{0} \preceq T S x_{0}=T x_{1}=x_{2}, \\
& x_{2}=T x_{1} \preceq S T x_{1}=S x_{2}=x_{3} .
\end{aligned}
$$

Continuing this process we have, $x_{1} \preceq x_{2} \preceq \cdots \preceq x_{n} \preceq x_{n+1} \preceq \cdots$. We may assume that $d\left(x_{2 n}, x_{2 n+1}\right)>0$, for every $n \in \mathbb{N}$. If not, then $x_{2 n}=x_{2 n+1}$ for some $n$ and for all those $n$, $x_{2 n}=x_{2 n+1}=S x_{2 n}$ and proof is finished.

Now, since $x_{2 n}$ and $x_{2 n+1}$ are comparable and taking $d\left(x_{2 n}, x_{2 n+1}\right)>0$ for $n=$ $0,1,2,3, \ldots$, we have

$$
\begin{aligned}
d\left(x_{2 n+1}, x_{2 n+2}\right)= & d\left(S x_{2 n}, T x_{2 n+1}\right) \\
\leq & \frac{a\left[d\left(x_{2 n}, x_{2 n+1}\right) d\left(x_{2 n}, x_{2 n+2}\right)+d\left(x_{2 n+1}, x_{2 n+2}\right) d\left(x_{2 n+o 1}, x_{2 n+1}\right)\right]}{d\left(x_{2 n}, x_{2 n+2}\right)+d\left(x_{2 n+1}, x_{2 n+1}\right)} \\
& +\frac{b d\left(x_{2 n}, x_{2 n+2}\right) d\left(x_{2 n+1}, x_{2 n+1}\right)}{d\left(x_{2 n}, x_{2 n+1}\right)+d\left(x_{2 n+1}, x_{2 n+2}\right)} \\
= & \frac{a d\left(x_{2 n}, x_{2 n+1}\right) d\left(x_{2 n}, x_{2 n+2}\right)}{d\left(x_{2 n}, x_{2 n+2}\right)} \\
= & a d\left(x_{2 n}, x_{2 n+1}\right) .
\end{aligned}
$$

Similarly, $d\left(x_{2 n}, x_{2 n+1}\right) \leq a d\left(x_{2 n-1}, x_{2 n}\right)$. Thus $d\left(x_{n+1}, x_{n+2}\right) \leq a d\left(x_{n}, x_{n+1}\right)$. Consequently

$$
d\left(x_{n+1}, x_{n+2}\right) \leq \operatorname{ad}\left(x_{n}, x_{n+1}\right) \leq \cdots \leq a^{n+1} d\left(x_{0}, x_{1}\right) \text { for all } n \geq 0 .
$$

Now for $m>n$, we have

$$
\begin{aligned}
d\left(x_{n}, x_{m}\right) & \leq d\left(x_{n}, x_{n+1}\right)+d\left(x_{n+1}, x_{n+2}\right)+\ldots+d\left(x_{m+1}, x_{m}\right) \\
& \leq a^{n} d\left(x_{0}, x_{1}\right)+a^{n+1} d\left(x_{0}, x_{1}\right)+\ldots+a^{m-1} d\left(x_{0}, x_{1}\right) \\
& \leq \frac{a^{n}}{1-a} d\left(x_{0}, x_{1}\right) .
\end{aligned}
$$

Therefore, $\left|d\left(x_{n}, x_{m}\right)\right| \leq \frac{a^{n}}{1-a}\left|d\left(x_{0}, x_{1}\right)\right|$, and so $\left|d\left(x_{n}, x_{m}\right)\right| \rightarrow 0$, as $m, n \rightarrow \infty$. It follows that $x_{n}$ is a Cauchy sequence in $X$. Since $X$ is complete, the sequence $x_{n}$ converges to a point $u$ in $X$. If $S$ or $T$ is continuous, then it is clear that $S u=u=T u$.

If neither $S$, nor $T$ is continuous, then by our assumption $x_{n} \preceq u$ for all $n$ in $\mathbb{N}$. We claim that $u$ is a fixed point of $S$. If not, then $d(u, S u)=z>0$.

Now from (2.5), we have

$$
\begin{aligned}
z \leq & d\left(u, x_{n+1}\right)+d\left(x_{n+1}, x_{n+2}\right)+d\left(x_{n+2}, S u\right) \\
\leq & d\left(u, x_{n+1}\right)+d\left(x_{n+1}, x_{n+2}\right)+d\left(S u, T x_{n+1}\right) \\
\leq & d\left(u, x_{n+1}\right)+d\left(x_{n+1}, x_{n+2}\right)+\frac{a\left[d(u, S u) d\left(u, T x_{n+1}\right)+d\left(x_{n+1}, T x_{n+1}\right) d\left(x_{n+1}, S u\right)\right]}{d\left(u, T x_{n+1}\right)+d\left(x_{n+1}, S u\right)} \\
& +\frac{b d\left(u, T x_{n+1}\right) d\left(x_{n+1}, S u\right)}{d(u, S u)+d\left(x_{n+1}, T x_{n+1}\right)} \\
= & d\left(u, x_{n+1}\right)+d\left(x_{n+1}, x_{n+2}\right)+\frac{a\left[d(u, S u) d\left(u, x_{n+2}\right)+d\left(x_{n+1}, x_{n+2}\right) d\left(x_{n+1}, S u\right)\right.}{d\left(u, x_{n+2}\right)+d\left(x_{n+1}, S u\right)} \\
& +\frac{b d\left(u, x_{n+2}\right) d\left(x_{n+1}, S u\right)}{d(u, S u)+d\left(x_{n+1}, x_{n+2}\right)} .
\end{aligned}
$$


Taking the limit as $n \rightarrow \infty$ gives $|z| \leq 0$, a contradiction and so $u=S u$. Therefore $S u=T u=u$.

Now suppose that set of common fixed points of $S$ and $T$ is totally ordered. We claim that common fixed point of $S$ and $T$ is unique. Assume on the contrary that $u$ and $v$ are distinct common fixed points of $S$ and $T$. By supposition, we can replace $x$ by $u$ and $y$ by $v$ in (2.5) to obtain

$$
\begin{aligned}
d(u, v) & =d(S u, T v) \\
& \leq \frac{a[d(u, S u) d(u, T v)+d(v, T v) d(v, S u)]}{d(u, T v)+d(v, S u)}+\frac{b d(u, T v) d(v, S u)}{d(u, S u)+d(v, T v)},
\end{aligned}
$$

which implies that $d(u, v)=d(S u, T v)=0$ and hence $u=v$.

Conversely, if $S$ and $T$ have only one common fixed point then the set of common fixed point of $S$ and $T$ being a singleton is totally ordered.

In Theorem 2.3, take $S=T$, to obtain the following corollary.

Corollary 2.4 Let $(X, \preceq)$ be a partially ordered set such that there exists a complete complex valued generalized metric $d$ on $X$ and $T$ be weakly increasing self-map on $X$. Suppose that, for every comparable $x, y \in X$, either

$$
\begin{aligned}
d(T x, T y) \leq & \frac{a[d(x, T x) d(x, T y)+d(y, T y) d(y, T x)]}{d(x, T y)+d(y, T x)} \\
& +\frac{b d(x, T y) d(y, T x)}{d(x, T x)+d(y, T y)}
\end{aligned}
$$

if $d(x, T y)+d(y, T x) \neq 0$ and $d(x, T x)+d(y, T y) \neq 0$, where $a, b \geq 0$ with $0 \leq a+$ $b<1$, or

$$
d(T x, T y)=0 \quad \text { if } d(x, T y)+d(y, T x)=0 \text { or } d(x, T x)+d(y, T y)=0 .
$$

If $T$ is continuous or for any nondecreasing sequence $\left\{x_{n}\right\}$ with $x_{n} \rightarrow z$ in $X$ we necessarily have $x_{n} \preceq z$ for all $n \in \mathbb{N}$. Then $T$ has a fixed point. Moreover, the set of fixed points of $T$ is totally ordered if and only if $T$ has one and only one fixed point.

Example 2.5 Let $X=\{1,2,3,4\}$ be endowed with order $x \preceq y$ if and only if $y \leq x$. Then $\preceq$ is a partial order in $X$. Define a generalized metric $d: X \times X \rightarrow \mathbb{C}$ as follows:

\begin{tabular}{ll}
\hline$(x, y)$ & $d(x, y)$ \\
\hline$(1,1),(2,2),(3,3),(4,4)$, & 0 \\
$(1,2),(2,1),(2,3),(3,2)$ & $e^{i \theta}$ \\
$(1,3),(3,1)$ & $3 e^{i \theta}$ \\
$(1,4),(4,1),(2,4),(4,2),(3,4),(4,3)$ & $5 e^{i \theta}$
\end{tabular}

It is straightforward to check that $(X, d)$ is a complex valued generalized metric space for $\theta \in\left[0, \frac{\pi}{2}\right]$. Note that

$$
d(1,3)=3 e^{i \theta} \not \leq 2 e^{i \theta}=d(1,2)+d(2,3),
$$

so $(X, d)$ is not a complex valued metric space. We define $S, T: X \rightarrow X$ by 


$$
S x=1 \text { for } x \in X \text { and } T x= \begin{cases}1, & \text { for } x \in\{1,2,3\} \\ 2, & \text { for } x=4 .\end{cases}
$$

Note that $S x \preceq T S x$ and $T x \preceq S T x$ for all $x \in X$. Now for $a=\frac{3}{5}$ and $b=\frac{1}{5}$, we consider the following cases:

(i) If $x \in X$ and $y \in X \backslash 4$, then we have $S x=T x=1$ and so $d(S x, T y)=0$ and (2.5) is satisfied obviously.

(ii) When $x=1$ and $y=4$, then $S x=1, T y=2$ and

$$
\begin{aligned}
d(S x, T y) & =e^{i \theta} \leq\left[\frac{25}{6} a+b\right] e^{i \theta} \\
& =\frac{a\left[(0)\left(e^{i \theta}\right)+\left(5 e^{i \theta}\right)\left(5 e^{i \theta}\right)\right]}{e^{i \theta}+5 e^{i \theta}}+\frac{b\left(e^{i \theta}\right)\left(5 e^{i \theta}\right)}{0+5 e^{i \theta}} \\
& =\frac{a[d(x, S x) d(x, T y)+d(y, T y) d(y, S x)]}{d(x, T y)+d(y, S x)}+\frac{b d(x, T y) d(y, S x)}{d(x, S x)+d(y, T y)} .
\end{aligned}
$$

(iii) For $x=2$ and $y=4, S x=1, T y=2$ and

$$
\begin{aligned}
d(S x, T y) & =e^{i \theta} \leq 5 a e^{i \theta} \\
& =\frac{a\left[\left(e^{i \theta}\right)(0)+\left(5 e^{i \theta}\right)\left(5 e^{i \theta}\right)\right]}{0+5 e^{i \theta}}+\frac{b(0)\left(5 e^{i \theta}\right)}{e^{i \theta}+5 e^{i \theta}} \\
& =\frac{a[d(x, S x) d(x, T y)+d(y, T y) d(y, S x)]}{d(x, T y)+d(y, S x)}+\frac{b d(x, T y) d(y, S x)}{d(x, S x)+d(y, T y)} .
\end{aligned}
$$

(iv) When $x=3$ and $y=4$, then $S x=1, T y=2$ and

$$
\begin{aligned}
d(S x, T y) & =e^{i \theta} \leq\left[\frac{28}{6} a+\frac{5}{8} b\right] e^{i \theta} \\
& =\frac{a\left[\left(3 e^{i \theta}\right)\left(e^{i \theta}\right)+\left(5 e^{i \theta}\right)\left(5 e^{i \theta}\right)\right]}{e^{i \theta}+5 e^{i \theta}}+\frac{b\left(e^{i \theta}\right)\left(5 e^{i \theta}\right)}{3 e^{i \theta}+5 e^{i \theta}} \\
& =\frac{a[d(x, S x) d(x, T y)+d(y, T y) d(y, S x)]}{d(x, T y)+d(y, S x)}+\frac{b d(x, T y) d(y, S x)}{d(x, S x)+d(y, T y)} .
\end{aligned}
$$

(v) In case $x=4$ and $y=4$, then $S x=1, T y=2$ and

$$
\begin{aligned}
d(S x, T y) & =e^{i \theta} \leq\left[5 a+\frac{5}{2} b\right] e^{i \theta} \\
& =\frac{a\left[\left(5 e^{i \theta}\right)\left(5 e^{i \theta}\right)+\left(5 e^{i \theta}\right)\left(5 e^{i \theta}\right)\right]}{5 e^{i \theta}+5 e^{i \theta}}+\frac{b\left(5 e^{i \theta}\right)\left(5 e^{i \theta}\right)}{5 e^{i \theta}+5 e^{i \theta}} \\
& =\frac{a[d(x, S x) d(x, T y)+d(y, T y) d(y, S x)]}{d(x, T y)+d(y, S x)}+\frac{b d(x, T y) d(y, S x)}{d(x, S x)+d(y, T y)} .
\end{aligned}
$$

Thus the conditions of Theorem 2.3 are satisfied with $a=\frac{3}{5}$ and $b=\frac{1}{5}$ where $a+b=$ $\frac{4}{5}<1$. Moreover, 1 is the unique common fixed point of $S$ and $T$.

\section{Periodic point results}

A fixed point $p$ of $T$ is also a fixed point of $T^{n}$ for every $n \in \mathbb{N}$. However, the converse is false. For example, consider, $X=[0,1]$, and define $T$ by $T x=1-x$. Then $T$ has a unique 
fixed point $\frac{1}{2}$ and every even iterate of $T$ is the identity map, which has every point of $[0,1]$ as a fixed point. On the other hand, if $X=[0, \pi], T x=\cos x$, then every iterate of $T$ has the same fixed point as $T$ (cf. $[1,11,16])$.

If a map $T$ satisfies $F(T)=F\left(T^{n}\right)$ for each $n \in \mathbb{N}$, where $F(T)$ is the set of fixed point of $T$, then it is said to have property $P$ [16]. The set $O(x, \infty)=x, T x, T^{2} x, \ldots$ is called the orbit of $x$.

Theorem 3.1 Let $(X, \preceq)$ be a partially ordered set such that there exists a complete complex valued generalizedmetric d on $X$. Let $T$ be a self-map on $X$ as in Corollary 2.2. If $O$ ( $x$, infty) is totally ordered, then $T$ has property $P$.

Proof From Corollary 2.4, $T$ has a fixed point. Let $u \in F\left(T^{n}\right)$. Now from (2.3), we have

$$
\begin{aligned}
d(u, T u)= & d\left(T\left(T^{n-1} u\right), T\left(T^{n} u\right)\right) \\
\leq & \frac{a_{1}\left[d\left(T^{n} u, T^{n} u\right)\left\{d\left(T^{n-1} u, T^{n+1} u\right)\right\}^{2}+d\left(T^{n-1} u, T^{n+1} u\right)\left\{d\left(T^{n} u, T^{n} u\right)\right\}^{2}\right]}{\left\{d\left(T^{n-1} u, T^{n+1} u\right)\right\}^{2}+\left\{d\left(T^{n} u, T^{n} u\right)\right\}^{2}} \\
& +\frac{a_{2} d\left(T^{n-1} u, T^{n+1} u\right) d\left(T^{n} u, T^{n} u\right)}{d\left(T^{n-1} u, T^{n+1} u\right)+d\left(T^{n} u, T^{n} u\right)} \\
& +a_{3} d\left(T^{n-1} u, T^{n} u\right)+a_{4} d\left(T^{n} u, T^{n+1} u\right)+a_{5} d\left(T^{n-1} u, T^{n} u\right) \\
= & \left(a_{3}+a_{5}\right) d\left(T^{n-1} u, T^{n} u\right)+a_{4} d\left(T^{n} u, T^{n+1} u\right) \\
= & \left(a_{3}+a_{5}\right) d\left(T^{n-1} u, u\right)+a_{4} d(u, T u),
\end{aligned}
$$

which implies

$$
d(u, T u) \leq \frac{a_{3}+a_{5}}{1-a_{4}} d\left(T^{n-1} u, u\right) .
$$

Put $\lambda=\frac{\left(a_{3}+a_{5}\right)}{1-a_{4}}$. Obviously $0 \leq \lambda<1$ and we have

$$
\begin{aligned}
d(u, T u) & =d\left(T u, T^{n} u\right) \\
& \leq \lambda d\left(T^{n-1} u, T^{n} u\right) \leq \lambda^{2} d\left(T^{n-2} u, T^{n-1} u\right) \leq \cdots \leq \lambda^{n} d(u, T u) .
\end{aligned}
$$

Since $0 \leq \lambda<1$ implies $d(u, T u)=0$ and $u=T u$.

Theorem 3.2 Let $(X, \preceq)$ be a partially ordered set such that there exists a complete complex valued generalized metric $d$ on $X$. Let $T$ be a self-map on $X$ as in Corollary 2.4. If $O(x, \infty)$ is totally ordered, then $T$ has property $P$.

Proof From Corollary 2.4, $T$ has a fixed point. Let $u \in F\left(T^{n}\right)$. Now from (2.7), we have

$$
\begin{aligned}
d(u, T u)= & d\left(T\left(T^{n-1} u\right), T\left(T^{n} u\right)\right) \\
\leq & \frac{a\left[d\left(T^{n-1} u, T^{n} u\right) d\left(T^{n-1} u, T^{n+1} u\right)+d\left(T^{n} u, T^{n+1} u\right) d\left(T^{n} u, T^{n} u\right)\right]}{d\left(T^{n-1} u, T^{n+1} u\right)+d\left(T^{n} u, T^{n} u\right)} \\
& +\frac{b d\left(T^{n-1} u, T^{n+1} u\right) d\left(T^{n} u, T^{n} u\right)}{d\left(T^{n-1} u, T^{n} u\right)+d\left(T^{n} u, T^{n+1} u\right)} \\
= & \frac{a d\left(T^{n-1} u, u\right) d\left(T^{n-1} u, T u\right)}{d\left(T^{n-1} u, T u\right)} \\
= & a d\left(T^{n-1} u, u\right) .
\end{aligned}
$$


Thus we have

$$
\begin{aligned}
d(u, T u) & =d\left(T u, T^{n} u\right) \\
& \leq a d\left(T^{n-1} u, T^{n} u\right) \leq a^{2} d\left(T^{n-2} u, T^{n-1} u\right) \\
& \leq \cdots \leq a^{n} d(u, T u) .
\end{aligned}
$$

Since $0 \leq a<1$ implies $d(u, T u)=0$ and $u=T u$.

\section{BA-cone metric spaces}

According to recent paper of Osturk and Basaris [19], it follows that complex valued metric space introduced in [7] and [23] is in fact BA-cone metric space, that is., cone metric space over a solid cone in commutative division Banach algebra $B$. Recall that a division algebra is an algebra with identity $e$, in which every nonzero element has an inverse called a unit, that is., $x$ is an unit if and only if there exists an inverse $y$ such that $x y=y x=e$. Then we write $y=x^{-1}$ and observe that $x^{-1}$ is unique when it exists (see [17] and [26]).***

Example 4.1 [19] Let $B=\mathbb{R}^{2}=\mathbb{C}, P=\{(x, y): x, y \geq 0\}, X=\mathbb{R}$ and $d: X \times X \rightarrow B$ defined by $d(x, y)=(|x-y|, \alpha|x-y|)$, where $\alpha \geq 0$ is a constant. Then $(X, d)$ is a BA-cone metric space over normal solid and monotone cone (see [13], (2.8) pp. 2593), since $B$ is a real commutative division Banach algebra.

Example 4.2 [19] Let $C_{\mathbb{R}}^{2}[0,1]$ be the space of all real functions on $[0,1]$ whose second derivative is continuous. We recall that for $a, b>0$, the space $C_{\mathbb{R}}^{2}[0,1]$ with the norm

$$
\|f\|=\|f\|_{\infty}+a\left\|f^{\prime}\right\|_{\infty}+b\left\|f^{\prime \prime}\right\|_{\infty}
$$

is a Banach space, where $\|f\|_{\infty}=\sup _{t \in[0,1]}|f(t)|$. This space is a Banach algebra if and only if $2 b \leq a^{2}$ (see [17], page 272).

If we take $X=B=C_{\mathbb{R}}^{2}[0,1]$ with the above norm and $P=\{u \in B: u \geq 0\}$, then $(X, d)$ becomes a cone metric space where

$$
d(x, y)(t):=\left(\sup _{t \in[0,1]}|x(t)-y(t)|\right) f(t)
$$

and $f:[0,1] \rightarrow \mathbb{R}, f(t)=e^{t}$. If $2 b>a^{2}$ then $B$ is not Banach algebra, that is., $(X, d)$ is not a BA-cone metric space.

It is worth to notice that all results from [7,14,23,30-32] and [33] are true and in the context of BA-cone metric spaces over normal solid and monotone cone. For example, Theorem 4. from [7] in this new context has the following form.

Theorem 4.3 Let $(X, d)$ be a complete BA-cone metric space over normal solid and monotone cone $P$ and let the mappings $S, T: X \rightarrow X$ satisfy:

$$
d(S x, T y) \preceq \lambda d(x, y)+\frac{\mu d(x, S x) d(y, T y)}{e+d(x, y)}
$$

for all $x, y \in X$, where $\lambda, \mu$ are nonnegative real with $\lambda+\mu<1$. Then $S, T$ have a unique common fixed point. 
Proof Let $x_{0} \in X$ be an arbitrary point and define

$$
x_{2 n+1}=S x_{2 n}, x_{2 n+2}=T x_{2 n+1}, \quad n=0,1,2, \ldots
$$

Then,

$$
\begin{aligned}
d\left(x_{2 n+1}, x_{2 n+2}\right) & =d\left(S x_{2 n}, T x_{2 n+1}\right) \\
& \preceq \lambda d\left(x_{2 n}, x_{2 n+1}\right)+\frac{\mu d\left(x_{2 n+1}, x_{2 n+2}\right) d\left(x_{2 n}, x_{2 n+1}\right)}{e+d\left(x_{2 n}, x_{2 n+1}\right) .}
\end{aligned}
$$

Since $d\left(x_{2 n}, x_{2 n+1}\right) \preceq e+d\left(x_{2 n}, x_{2 n+1}\right)$ then $\left\|d\left(x_{2 n}, x_{2 n+1}\right)\right\| \leq\left\|e+d\left(x_{2 n}, x_{2 n+1}\right)\right\|$. Hence, $\left\|d\left(x_{2 n+1}, x_{2 n+2}\right)\right\| \leq \frac{\lambda}{1-\mu}\left\|d\left(x_{2 n}, x_{2 n+1}\right)\right\|$, that is., for any $m>n:\left\|d\left(x_{m}, x_{n}\right)\right\| \preceq$ $\frac{h^{n}}{1-h}\left\|d\left(x_{0}, x_{1}\right)\right\|$ where $h=\frac{\lambda}{1-\mu} \in[0,1)$. Since, $\frac{h^{n}}{1-h}\left\|d\left(x_{0}, x_{1}\right)\right\| \rightarrow 0$ it follows that $\left\|d\left(x_{m}, x_{n}\right)\right\| \rightarrow 0$. This implies that $\left\{x_{n}\right\}$ is a Cauchy sequence. Hence, there exists $u \in X$ such that $x_{n} \rightarrow u$. First, we show that $S u=u$, otherwise $d(u, S u) \succ \theta$. Then, we have

$$
\begin{aligned}
d(u, S u) & \preceq d\left(u, x_{2 n+2}\right)+d\left(T x_{2 n+1}, S u\right) \\
& \preceq d\left(u, x_{2 n+2}\right)+\lambda d\left(x_{2 n+1}, u\right)+\frac{\mu d\left(x_{2 n+1}, x_{2 n+2}\right) d(u, S u)}{e+d\left(u, x_{2 n+1}\right)} .
\end{aligned}
$$

Since $\frac{\mu d\left(x_{2 n+1}, x_{2 n+2}\right) d(u, S u)}{e+d\left(u, x_{2 n+1}\right)} \rightarrow \theta$ in Banach algebra $B$, according to ([13], (2.9) pp. 2593) it follows that $d(u, S u)=\theta$, that is., $S u=u$. A contradiction. It follows similarly that $u=T u$.

The proof for uniqueness is as in [7].

Further, Theorem 2.1 from [23] in the context of BA-cone metric spaces has the following form. The proof is similarly to the previous one and therefore we omit it.

Theorem 4.4 Let $(X, d)$ be a complete BA-cone metric space over normal solid and monotone cone $P$ and let the mappings $S, T: X \rightarrow X$ satisfy:

$$
d(S x, T y) \preceq \lambda d(x, y)+\frac{\mu d(x, S x) d(y, T y)+\gamma d(y, S x) d(x, T y)}{e+d(x, y)}
$$

for all $x, y \in X$, where $\lambda, \mu, \gamma$ are nonnegative reals with $\lambda+\mu+\gamma<1$. Then $S, T$ have a unique common fixed point.

Theorem 4.5 Also, previous Theorems 2.1, 2.3, 3.1, 3.2 as well as Corollaries 2.2 and 2.4 are true in the context of BA-cone metric spaces over normal solid and monotone cone.

Open Access This article is distributed under the terms of the Creative Commons Attribution License which permits any use, distribution, and reproduction in any medium, provided the original author(s) and the source are credited.

\section{References}

1. Abbas, M., Rhoades, B.E.: Fixed and periodic point results in cone metric spaces. Appl. Math. Lett. 22, 511-515 (2009)

2. Abbas, M., Nazir, T., Radenović, S.: Common fixed points of four maps in partially ordered metric spaces. Appl. Math. Lett. 24, 1520-1526 (2011)

3. I. Altun and H. Simsek, Some fixed point theorems on ordered metric spaces and application, Fixed Point Theory Appl., vol. 2010, Article ID 621492. 
4. Altun, I., Damjanovic, B., Djorić, D.: Fixed point and common fixed point theorems on ordered cone metric spaces. Appl. Math. Lett. 3(23), 310-316 (2010)

5. Amini-Harandi, A., Emami, H.: A fixed point theorem for contraction type maps in partially ordered metric spaces and application to ordinary differential equations. Nonlinear Anal. 72(5), 2238-2242 (2010)

6. Azam, A., Arshad, M.: Kannan fixed point theorem on generalized metric spaces. J. Nonlinear Sci. Appl. 1, 45-48 (2008)

7. Azam, A., Fisher, B., Khan, M.: Common fixed point theorems in complex valued metric spaces. Numer. Funct. Anal. Optim. 32(3), 243-253 (2011)

8. Branciari, A.: A fixed point theorem of Banach-Caccippoli type on a class of generalized metric spaces. Public. Math. Debrecen 57, 31-37 (2000)

9. Ćirić, L., Abbas, M., Saadati, R., Hussain, N.: Common fixed points of almost generalized contractive mappings in ordered metric spaces. Appl. Math. Comput. 217, 5784-5789 (2011)

10. Dhage, B.C.: Generalized metric spaces with fixed point. Bull. Calcutta Math. Soc. 84, 329-336 (1992)

11. Gornicki, J., Rhoades, B.E.: A general fixed point theorem for involutions. Indian J. Pure Appl. Math. 27, 13-23 (1996)

12. Harjani, J., Sadarangani, K.: Fixed point theorems for weakly contractive mappings in partially ordered sets. Nonlinear Anal. 71, 3403-3410 (2009)

13. Janković, S., Kadelburg, Z., Radenović, S.: On cone metric spaces: a survey. Nonlinear Anal. 74, 2591$2601(2011)$

14. Klin-eam, C., Suanoom, C.: Some common fixed point theorems for generalized contractive type mappings on complex valued metric spaces. Abstr. Appl. Anal. 2013 (2013). doi:10.1155/2013/604215

15. Haung, L.-G., Zhang, X.: Cone metric spaces and fixed point theorems of contractive mappings. J. Math. Anal. Appl. 332, 1468-1476 (2007)

16. Jeong, G.S., Rhoades, B.E.: Maps for which $F(T)=F\left(T^{n}\right)$. Fixed Point Theory Appl. 6, 87-131 (2005)

17. Madox, I.J.: Elements of Functional Analysis. Cambridge University Press, Cambridge (1970)

18. Nieto, J.J., Lopez, R.R.: Contractive mapping theorems in partially ordered sets and applications to ordinary differential equations. Order 22, 223-239 (2005)

19. Ozturk, M., Basaris, M.: On some common fixed point theorems with rational expressions on cone metric spaces over a Banach algebra. Hacettepe J. Math. Stat. 41(2), 211-222 (2012)

20. Radenović, S., Rhoades, B.E.: Fixed point theorem for two non-self mappings in cone metric spaces. Comput. Math. Appl. 57, 1701-1707 (2009)

21. Radenović, S., Kadelburg, Z.: Generalized weak contractions in partially ordered metric spaces. Comput. Math. Appl. 60, 1776-1783 (2010)

22. Ran, A.C.M., Reurings, M.C.B.: A fixed point theorem in partially ordered sets and some application to matrix equations. Proc. Am. Math. Soc. 132, 1435-1443 (2004)

23. Rouzkard, F., Imbdad, M.: Some common fixed point theorems on complex valued metric spaces. Comput. Math. Appl. (2012). doi:10.1016/j.camwa.2012.02.063

24. Saadati, R., Vaezpour, S.M., Vetro, P., Rhoades, B.E.: Fixed point theorems in generalized partially ordered $G-$ metric spaces. Math. Comput. Model. 52, 797-801 (2010)

25. Rezapour, S., Hamlbarani, R.: Some notes on the paper 'cone metric spaces and fixed point theorems of contractive mappings'. J. Math. Anal. Appl. 345, 719-724 (2008)

26. Rudin, W.: Functional Analysis, 2nd edn. McGraw-Hill International Edition, New York (1991)

27. Samet, B.: A fixed point theorem in a generalized metric space for mappings satisfying a contractive condition of integral type. Int. J. Math. Anal. 3(26), 1265-1271 (2009)

28. Samet, B.: Discussion on: A fixed point theorem of Banach-Caccioppoli type on a class of generalized metric spaces by A. Branciari. Public. Math. Debrecen 76, 493-494 (2010)

29. Sarma, I.R., Rao, J.M., Rao, S.S.: Contractions over generalized metric spaces. J. Nonlinear Sci. Appl. 2(3), 180-182 (2009)

30. Sastry, K.P.R., Naidu, G.A., Bekeshie, T.: Metrizability of complex valued metric spaces and some remarks on fixed point theorems in complex valued metric spaces. Int. J. Math. Archive 3(7), 2686-2690 (2012)

31. Sitthikul, K., Saejung, S.: Some fixed point theorems in complex valued metric space. Fixed Point Theory Appl. 2012, 189 (2012)

32. Verma, R.K., Pathak, H.K.: Common fixed point theorems using property (E.A) in complex-valued metric spaces. Thai J Math. 11(2), 347-355 (2013)

33. Sintunavarat, Wutiphol, Kumam, Poom: Generalized common fixed point theorems in complex valued metric spacers and applications. J. Inequal Appl 2012, 84 (2012) 